\title{
Lactobacillus fermentum CECT5716 supplementation in rats during pregnancy and lactation affects mammary milk composition
}

\author{
Ignasi Azagra-Boronat, ${ }^{1,2} \odot$ Alba Tres, ${ }^{2,3} \oplus$ Malén Massot-Cladera, ${ }^{1,2} \odot$ Àngels Franch,,${ }^{1,2} \oplus$ \\ Margarida Castell, ${ }^{1,2}$ (1) Francesc Guardiola, ${ }^{2,3}$ (1) Francisco J. Pérez-Cano, ${ }^{1,2 *}$ (1) \\ and M. José Rodríguez-Lagunas ${ }^{1,2}$ (i) \\ ${ }^{1}$ Physiology Section, Department of Biochemistry and Physiology, Faculty of Pharmacy and Food Science, University of Barcelona, \\ Barcelona 08028, Spain \\ ${ }^{2}$ Nutrition and Food Safety Research Institute, Santa Coloma de Gramenet 08921, Spain \\ ${ }^{3}$ Department of Nutrition, Food Science and Gastronomy, Torribera Food Science Campus, Faculty of Pharmacy and Food Science, \\ University of Barcelona, Santa Coloma de Gramenet 08921, Spain
}

\section{ABSTRACT}

Lactobacillus fermentum CECT5716 has shown immunomodulatory action and reduction of infections; therefore, it is suggested to be appropriate for use in early life. The present study aimed to assess the effects of the supplementation of $L$. fermentum CECT5716 in rats during gestation and lactation periods on the composition of some mammary milk components such as microbiota, fatty acid (FA) profile, and immunoglobulins. Wistar rats were supplemented by oral gavage with $10^{10} \mathrm{cfu} / \mathrm{d}$ of Lactobacillus fermentum CECT5716 $(\mathrm{n}=6)$ or vehicle $(\mathrm{n}=6)$ for $5 \mathrm{wk}$, comprising the $3 \mathrm{wk}$ of gestation and the first $2 \mathrm{wk}$ of lactation. At the end of the intervention, milk, mammary glands, and cecal contents were obtained for the tracking of the probiotic strain by nested PCR-quantitative PCR. Additionally, milk samples were used for the analysis of microbiota by $16 \mathrm{~S}$ rRNA sequencing, FA by gas chromatographyflame ionization detector, and immunoglobulin by Luminex (Luminex Corporation, Austin, TX). Although L. fermentum CECT5716 administration did not modify the overall composition of milk microbiota, the strain was detected in $50 \%$ of the milk samples of rats supplemented with the probiotic. Moreover, probiotic administration induced beneficial changes in the FA composition of milk by increasing total PUFA, including linoleic and $\alpha$-linolenic acids, and decreasing the proportion of palmitic acid. Finally, the milk of the rats treated with the probiotic showed a 2 -fold increase of IgA levels. The supplementation with L. fermentum CECT5716 during pregnancy and lactation periods improved the milk composition of FA and immunoglobu-

Received August 2, 2019.

Accepted December 2, 2019.

*Corresponding author: franciscoperez@ub.edu lins. These effects were not linked to the presence of the strain in milk, thus suggesting that the mechanism is connected to intestinal compartment. These findings provide novel insight into a potential new approach for infants to benefit from better nutrition, development of a healthy immune system and microbiota, and protection from gastrointestinal infections.

Key words: Lactobacillus, fatty acid, immune system, microbiota

\section{INTRODUCTION}

Human milk is the biological normative standard that provides optimal nutrition for infants to achieve proper growth and development (Ballard and Morrow, 2013). Human milk is rich in fatty acids (FA) that provide energy and lipid-soluble vitamins (Koletzko, 2016). Moreover, PUFA contribute to the immunity of the newborn, as they can regulate the production of cytokines, eicosanoids, and cell activity (Gottrand, 2008; Ganapathy, 2009). Breast milk also contains immunoglobulins that supplement the yet immature production in the newborn and help to protect against infections, namely those affecting the intestinal tract (Jackson and Nazar, 2006). In addition, breastfeeding is a physiological source of commensal and potentially probiotic bacteria to the infant; a baby consuming about 800 $\mathrm{mL}$ of breast milk daily would be ingesting $10^{5}$ to $10^{7}$ bacteria (Fernández et al., 2013; Jeurink et al., 2013).

Adaptations in body composition and physiology are induced throughout gestation and lactation periods, increasing the maternal nutritional requirements (Mecacci et al., 2015). It is well known that the composition of breast milk is sensitive to maternal dietary habits, influencing the quality of breast milk and therefore the healthy growth and development of the newborn (Tian et al., 2019). In this context, the use of probiotics during gestation and lactation periods may bring multiple 
clinical benefits to both the mother and infant (Reid et al., 2013; Swartwout and Luo, 2018). However, not all probiotic strains exert the same effects on health, and therefore the effects of one probiotic cannot be generalizable to others (McFarland et al., 2018).

Lactic acid bacteria, such as Lactobacillus, are commonly used as probiotics. In addition, Lactobacillus is a subdominant genus in the intestine (Archer and Halami, 2015) and is also naturally present in breast milk (Martín et al., 2003; Gregora, 2018). In this regard, several studies have shown vertical mother-neonate transfer of maternal gut bacteria, including Lactobacillus (Jiménez et al., 2010; Martín et al., 2012) and that maternal dendritic cells and macrophages can engulf live bacteria from the intestine and transport them to breast milk through the circulation (Fernández et al., 2013).

Lactobacillus fermentum CECT5716 is a probiotic strain isolated from breast milk (Martín et al., 2003) with reported beneficial properties and favorable safety and tolerance when administered in infants and mothers (Díaz-Ropero et al., 2007; Gil-Campos et al., 2012; Maldonado-Lobón et al., 2015b; Bond et al., 2017). Among these properties, L. fermentum CECT5716 has been shown to modulate the immune system in vivo and in vitro (Díaz-Ropero et al., 2007; Pérez-Cano et al., 2010; Robles-Vera et al., 2018), to enhance the effects of influenza vaccination in adults (Olivares et al., 2007), to reduce gastrointestinal and upper respiratory tract infections in infants (Maldonado et al., 2012), and to be effective in the treatment of infectious mastitis during lactation (Arroyo et al., 2010; Maldonado-Lobón et al., 2015a; Bond et al., 2017).

Despite growing evidence on the effects of Lactobacillus during pregnancy and lactation, there is still relatively little information regarding the assessment of the quality of the milk. Therefore, the present study aimed to investigate the effects of the supplementation of $L$. fermentum CECT5716 in rats during gestation and lactation periods on the profile of FA, immunoglobulin, and microbiota of the milk, all factors affecting neonatal immune development.

\section{MATERIALS AND METHODS}

\section{Animals}

Wistar adult rats (18 females and 3 males, RjHan:WI) were obtained from Janvier Labs (Le Genest-Saint-Isle, France) and individually housed in cages containing bedding with large fibrous particles. Dams were given a standard diet corresponding to the American Institute of Nutrition 93G formulation (Reeves et al., 1993; Teklad Global Diet 2014, Envigo, Indianapolis, IN) and water ad libitum. To allow the animals to stabilize in the new environment, an acclimatization period of $7 \mathrm{~d}$ was established. Then, animals were crossed by placing 2 randomly selected females inside the cage of each of the males for $24 \mathrm{~h}$. After crossing, 12 pregnant dams were individually housed, monitored daily, and allowed to deliver naturally. The day of birth was established as d 1 of life. On d 2, litters were culled to 8 pups per lactating dam, with free access to maternal milk and a rat diet. Animals were housed under controlled conditions of temperature and humidity in a $12 \mathrm{~h}$ light, $12 \mathrm{~h}$ dark cycle, in the Faculty of Pharmacy and Food Science animal facility (University of Barcelona, Spain).

All experimental procedures were conducted in accordance with the institutional guidelines for the care and use of laboratory animals and were approved by the Ethical Committee for Animal Experimentation of the University of Barcelona and the Catalan Government (CEEA-UB Ref. 486/16 and DAAM9268, respectively), which are in full compliance with national legislation following EU-Directive 2010/63/EU for the protection of animals used for scientific purposes.

\section{Experimental Design and Sample Collection}

Dams were supplemented by oral gavage with $10^{10}$ cfu/d of L. fermentum CECT5716 ( $\mathbf{L F}$ group, $\mathrm{n}=6$ ) or vehicle (water with $20 \%$ maltodextrin; REF group, $\mathrm{n}=6$ ) for $5 \mathrm{wk}$, comprising the $3 \mathrm{wk}$ of gestation and the first 2 wk of lactation. At the end of this period, the dams were anesthetized intramuscularly with 10 $\mathrm{mg} / 100 \mathrm{~g}$ of ketamine (Merial Laboratories S.A., Lyon, France) and administered intraperitoneally with 2 IU of oxytocin (Syntocinón $10 \mathrm{IU} / \mathrm{mL}$, Alfasigma, Bologna, Italy). Milking was initiated after $5 \mathrm{~min}$ of oxytocin administration by gentle manual stimulation from the base to the top of the teat. The milk was collected into a pipette tip, which was attached to a manual vacuum device (Nahrinel, Novartis, Basel, Switzerland; Ramírez-Santana et al., 2009). Afterward, dams were re-anesthetized with ketamine $(90 \mathrm{mg} / \mathrm{kg})$ and xylazine (10 mg/kg; Bayer A.G., Leverkusen, Germany) and the mammary gland (MG) was extracted and frozen at $-80^{\circ} \mathrm{C}$ to quantify the amount of $\operatorname{IgA}$ and $\operatorname{IgM}$. The cecal content (CC) was also obtained and stored at $-80^{\circ} \mathrm{C}$. Finally, MG, CC, and milk were used to determine the presence of the probiotic.

\section{Lipid Extraction, Methylation, and Quantification of FA in Milk}

The analysis of FA in milk was performed as follows: the lipid fraction of the milk samples was extracted 
with a mix of $\mathrm{CHCl}_{3} / \mathrm{MeOH} 2: 1$ ( vol/vol), and then derivatized to obtain the FAME, which were determined by GC in an Agilent 4890D chromatograph (Agilent Technologies, Waldbronn, Germany) equipped with a SP-2380 capillary column (60 m, $0.25 \mathrm{~mm}$ i.d., $0.2 \mu \mathrm{m}$, Supelco, Bellefonte, PA), a split-splitless injector set at $270^{\circ} \mathrm{C}$, and a flame ionization detector set at $300^{\circ} \mathrm{C}$. The split ratio was 1:30. For FAME separation, the oven program was configured as follows: initial temperature $150^{\circ} \mathrm{C}$ (held at this temperature for $1 \mathrm{~min}$ ) up to $180^{\circ} \mathrm{C}$ at $3^{\circ} \mathrm{C} / \mathrm{min}$, from $180^{\circ} \mathrm{C}(0.5 \mathrm{~min})$ up to $220^{\circ} \mathrm{C}$ at $14.5^{\circ} \mathrm{C} / \mathrm{min}$, and from $220^{\circ} \mathrm{C}(3 \mathrm{~min})$ up to $250^{\circ} \mathrm{C}$ at $9.9^{\circ} \mathrm{C} / \mathrm{min}$, maintaining $9.5 \mathrm{~min}$ at $250^{\circ} \mathrm{C}$. The carrier gas was hydrogen $\left(1.72 \times 10^{5} \mathrm{~Pa}\right)$. Two microliters of the samples was injected, and the FA were identified by comparing the retention time with a standard mix (Supelco 37 component FAME Mix, Sigma-Aldrich Co., St. Louis, MO). A total of 26 FA were identified. The quantification was performed by peak area normalization (the quantitative results are obtained by expressing the area of a given peak as a percentage of the sum of the areas of all the identified peaks).

\section{Quantification of Immunoglobulins and Cytokines in Milk and MG}

The quantification of immunoglobulins (IgM, IgG1, $\operatorname{IgG} 2 \mathrm{a}, \operatorname{IgG} 2 \mathrm{~b}, \operatorname{Ig} \mathrm{G} 2 \mathrm{c}$, and $\operatorname{IgA}$ ) in lactic serum and MG and cytokines (IFN $\gamma, \mathrm{TNF} \alpha$, IL-4, IL-6, IL-10, and IL-12) in lactic serum was performed at the end of the study, as previously described (Azagra-Boronat et al., 2018). Briefly, specific color-coded capture beads were bound to the analyte of interest. Then, different detection antibodies conjugated to phycoerythrin were added for the detection of immunoglobulin. For the detection of cytokines, antibodies conjugated to biotin were added, followed by an incubation with streptavidin-phycoerythrin. The specific concentration of each analyte was obtained by MAGPIX analyzer (Luminex Corporation, Austin, TX) at the Cytometry Service of the Science and Technology Centres of the University of Barcelona (CCiT-UB). Assay sensitivity was as follows: $0.02 \mathrm{ng} / \mathrm{mL}$ for IgM, $0.78 \mathrm{ng} / \mathrm{mL}$ for IgG1, 0.02 $\mathrm{ng} / \mathrm{mL}$ for IgG2a, $0.11 \mathrm{ng} / \mathrm{mL}$ for IgG2b, $0.19 \mathrm{pg} / \mathrm{mL}$ for IgG2c, $0.48 \mathrm{pg} / \mathrm{mL}$ for IgA, $0.6 \mathrm{pg} / \mathrm{mL}$ for IFN- $\gamma$, $0.4 \mathrm{pg} / \mathrm{mL}$ for TNF- $\alpha, 0.1 \mathrm{pg} / \mathrm{mL}$ for IL- $4,1.9 \mathrm{pg} /$ $\mathrm{mL}$ for IL-6, $1.6 \mathrm{pg} / \mathrm{mL}$ for IL-10, and $5.9 \mathrm{pg} / \mathrm{mL}$ for IL-12p70.

\section{Analysis of Milk Microbiota Composition}

Genomic DNA was extracted from milk samples (n $=6 /$ group) using the DNeasy Blood and Tissue Mini kit (Qiagen, Madrid, Spain) and amplified following the 16S Metagenomic Sequencing Library Illumina 15044223 B protocol (Illumina Inc., San Diego, CA). Image analysis, base calling, and data quality assessment were performed in the MiSeq instrument (Illumina Inc.). Sequences were merged and processed as previously described using a Pair-End read merger (PEAR v 0.9.6, Exelixis Lab, Heidelberg, Germany) and Cutadapt v1.8.1 (Martin, 2011).

Two of the 12 milk samples were contaminated and were discarded from the microbiota study. The qualitative presence or absence of genera was represented in a Venn diagram. A bacterial group was considered as present by establishing a cutoff of 4 animals displaying proportions higher than $0.001 \%$, whereas the bacterial groups detected in 3 or less animals were regarded as absent.

A principal component analysis (PCA) of the different genera was also performed. To develop the model, Simca v14.1 was used (Umetrics, Umeå, Sweden). Two data matrices were constructed consisting of 10 rows and 193 variables corresponding to the taxonomic analysis of genera. The PCA was conducted on both data matrices to explore the presence of any natural clustering in the data. In the preprocessing of the PCA, the mean-centering and unit variance scaling were applied.

\section{Detection of L. fermentum CECT5716 in Rat Samples}

Detection of probiotic in milk, MG and $\mathrm{CC}$ was performed by PCR techniques as described by Gil-Campos et al. (2012). The samples were weighed and homogenized in a FastPrep-24 instrument (MP Biomedicals Inc., Santa Ana, CA) for $40 \mathrm{~s}$. The DNA was obtained following the instructions of the FastDNA kit (MP Biomedicals Inc.). The probiotic genome was detected following a nested PCR-based strategy. We performed a first standard amplification using the following primers at $500 \mathrm{n} M$ : HSL40_126D (5'-GCTTGCCGCTTCTCTGGT-3') and HSL40-126 (5'-CAACGACGATGAACACCACTT- $\left.3^{\prime}\right)$. The PCR conditions were an initial denaturing step for $5 \mathrm{~min}$ at $95^{\circ} \mathrm{C}$, followed by 40 cycles at $95^{\circ} \mathrm{C}$ for $30 \mathrm{~s}, 46^{\circ} \mathrm{C}$ for $30 \mathrm{~s}$ and $72^{\circ} \mathrm{C}$ for $30 \mathrm{~s}$, and a final extension for $3 \mathrm{~min}$ at $72^{\circ} \mathrm{C}$. The result of the amplification was an amplicon of $222 \mathrm{bp}$. The second amplification was a Taq-Man-based PCR assay, which target sequence was located within the product of the first PCR. The forward primer was 5'-TCAACGGCCCCTTCAATACA- $3^{\prime}$, the reverse primer used was 5'-GACCTAATTCACGTCAAACATATTTCAC-3' and the probe labeled with VIC and CSY was 5'-AGTGGTGAGATGCCCAGTGTTCCCG-3'. Quantitative PCR assays were performed in duplicate for 
each sample using an ABI PRISM7700 Sequence Detection System (Applied Biosystems, Foster City, CA) in the CCiT-UB.

\section{Statistical Analysis}

The Statistical Package for the Social Sciences (SPSS v22.0, IBM, Chicago, IL) was used for the statistical analysis. Student's $t$-test was used to analyze statistical differences. Correlations between levels of immunoglobulin in MG and milk were studied with the calculation of Spearman's correlation coefficient. Significant differences were established when $P<0.05$.

\section{RESULTS}

\section{Detection of L. fermentum CECT5716}

The analysis of the presence of L. fermentum CECT5716 in milk, MG, and CC was performed at the end of the study by means of a specific nested-PCR combined with quantitative PCR (Table 1). The probiotic was not present in any of the REF samples. As expected, all animals receiving the probiotic showed its presence in the CC. However, half of the milk samples $(3 / 6)$ in the LF group were positive for L. fermentum CECT5716. In addition, it was also detected in $1 / 6$ of the MG in the LF group, which matched with one of the positive samples found in milk.

\section{Milk Microbiota Composition}

The microbiota of the milk was examined based on the sequencing of fragments V3-V4 of $16 \mathrm{~S}$ rRNA gene (Figure 1). More than $75 \%$ of the bacteria of the milk belonged to the Proteobacteria and Firmicutes phyla. The supplementation of dams with $L$. fermentum CECT5716 during pregnancy and lactation periods did not modify the microbiota abundance profile of milk at the levels of phylum, family, and main genera (Figure 1A-D). However, when analyzing all the genera through a qualitative point of view, as those present in the Venn diagram (Figure 1E), it was observed that 44 genera were shared between the 2 groups, whereas 8 genera were present in the REF group only and 23 genera in the LF group only. Furthermore, with the cutoff used for the calculation of presence and absence of the bacteria, Actinomyces in the REF group and Arthrobacter, Brevundimonas, and Mycobacterium in the LF group seemed to be the ones that were the most differential. Finally, the PCA score plot of genera (Figure $1 \mathrm{~F})$ revealed that the microbiota of milk samples did not clearly separate in 2 groups.

\section{FA Composition}

The rat FA composition in milk was $\sim 65 \%$ SFA, $\sim 15 \%$ MUFA, and $20 \%$ PUFA. The changes of milk FA due to $L$. fermentum CECT5716 supplementation were analyzed (Figure 2A). The LF group displayed $2 \%$ less palmitic acid (16:0, fold change: $-0.072, P<$ $0.05)$, which is the main FA found in milk, accounting for $\sim 30 \%$ of the total FA. Moreover, although not significantly, other SFA such as 14:0, 20:0, or 22:0 also displayed negative fold changes. Conversely, the total PUFA were found in higher proportions $(P<0.05)$, as displayed by positive fold changes in all the PUFA analyzed, with significant differences $(P<0.05)$ in linoleic acid (18:2n-6) and $\alpha$-linolenic acid (18:3n-3).

The natural clustering of data was analyzed through PCA (Figure 2B and 2C). Interestingly, 2 separate clusters could be identified in the score plot (Figure 2B), one belonging to the REF group and one to the LF group. Nevertheless, one of the REF samples behaved differently, as it did not group with the others. The loading plot (Figure 2C) shows how strongly each variable influences the principal components, and therefore to what extent each variable explains the variance found due to the supplementation. The variance in the REF cluster was strongly influenced by even-chain SFA, such as 16:0 and 14:0, and the variance in the LF cluster was rather influenced by MUFA and PUFA, such as 18:2n- 6 and 22:6n-3.

Table 1. Detection of Lactobacillus fermentum CECT5716 in rat samples ${ }^{1}$

\begin{tabular}{|c|c|c|c|c|c|c|c|c|c|c|c|c|}
\hline \multirow[b]{2}{*}{ Item } & \multicolumn{6}{|c|}{ REF } & \multicolumn{6}{|c|}{ LF } \\
\hline & 1 & 2 & 3 & 4 & 5 & 6 & 7 & 8 & 9 & 10 & 11 & 12 \\
\hline $\begin{array}{l}\text { CC } \\
\text { Milk } \\
\text { MG }\end{array}$ & & & & & & & $\begin{array}{l}X \\
X\end{array}$ & $\mathrm{X}$ & $\begin{array}{l}X \\
X\end{array}$ & $\mathrm{X}$ & $\mathrm{X}$ & $\begin{array}{l}X \\
X \\
X\end{array}$ \\
\hline
\end{tabular}


A
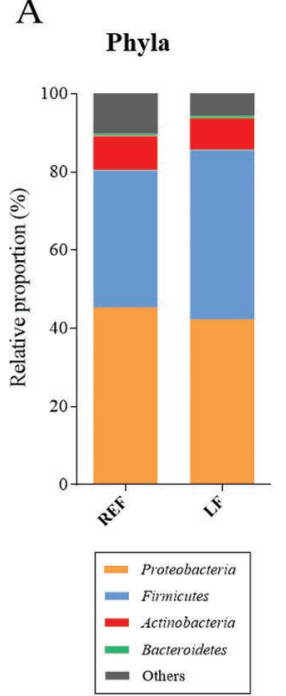

B
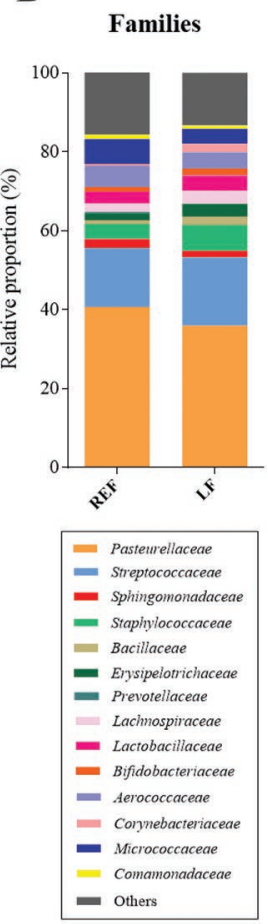

$\mathrm{C}$

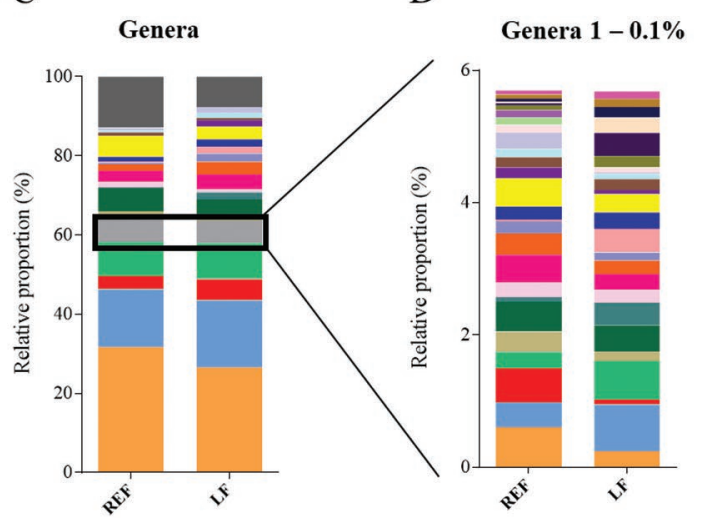

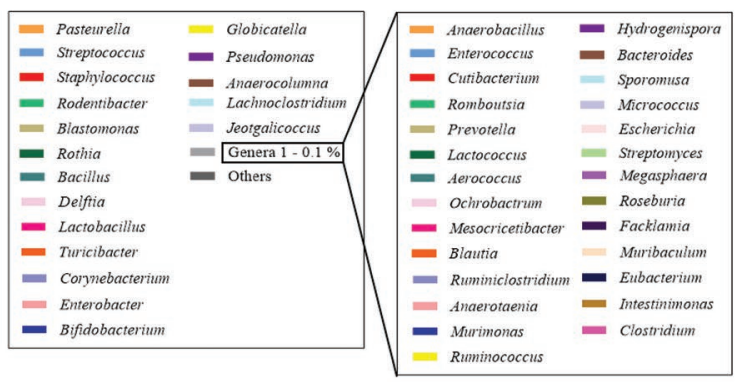
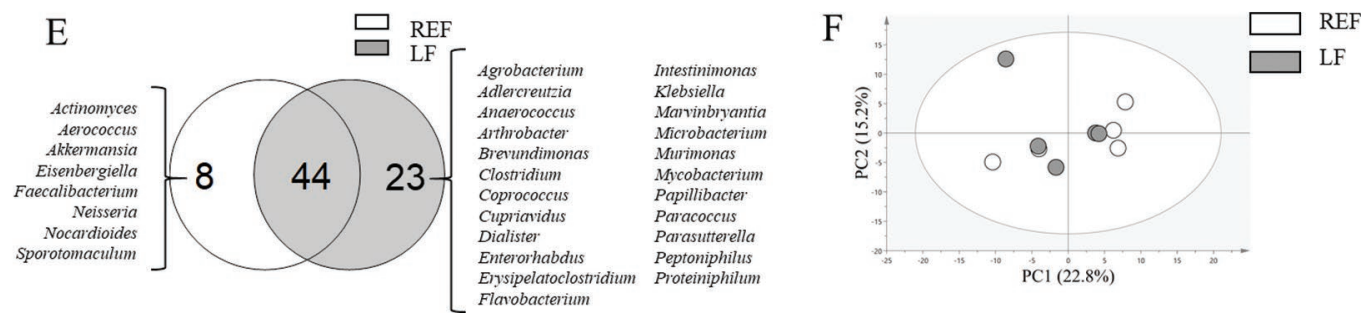

Figure 1. Assessment of Lactobacillus fermentum CECT5716 (LF) supplementation on milk microbiota. The sequencing of the amplicon targeting the V3 to V4 region of the 16S rRNA was performed following the 16S Metagenomic Sequencing Library Illumina 15044223 B protocol (Illumina Inc., San Diego, CA). The main taxonomic rank abundances, corresponding to (A) phylum, (B) family, (C) genera, and (D) genera $1-0.1 \%$, are represented by stacked bars. The qualitative assessment of microbiota was represented (E) in a Venn diagram at the level of genera. Finally, the natural clustering of samples was assessed (F) by principal component analysis score plot at the level of genera. Results were derived from $\mathrm{n}=5$ per group. $\mathrm{PC} 1=$ principal component 1 ; $\mathrm{PC} 2=$ principal component 2 ; $\mathrm{REF}=$ reference.

\section{Immunoglobulin and Cytokine Profile}

The immunoglobulin content of rat MG and milk was determined (Figure 3). The relative amount of immunoglobulin was similar in both compartments, although the milk showed higher IgA compared with the MG ( $\sim 10$ and $\sim 4 \%$, respectively, $P<0.05$ ). Moreover, the supplementation with LF showed a 2-fold increase of the amount of IgA in milk (Figure 3A). Although no changes were seen in the MG, a similar pattern compared with milk was observed: the LF group displayed negative fold changes in Th1 immunoglobulin (IgG2b and IgG2c) and positive fold changes in the Th2 immunoglobulin (IgG1 and IgG2a). Therefore, the ratio Th1/Th2 showed a trend toward lower values (i.e.,
Th2-biased) in both compartments $(P=0.07$ in both milk and MG).

The correlations between immunoglobulin levels in the MG and milk were explored and plotted in a heat map (Figure 3B). Positive correlations were found $(P$ $<0.05$ ) for matching immunoglobulins when comparing both compartments (e.g., $\operatorname{IgA}$ in $\mathrm{MG}$ and $\operatorname{IgA}$ in milk), with the exception of IgM. Furthermore, in all cases the ratio Th1/Th2 correlated positively with Th1 immunoglobulin but not Th2 immunoglobulin.

The concentration of IFN $\gamma$, IL-6, IL-12, and TNF $\alpha$ cytokines in milk were under the limit of detection. In addition, although IL- 4 and IL-10 were detected $(\sim 0.2$ and $\sim 30 \mathrm{pg} / \mathrm{mL}$ ), no differences between groups were observed. 


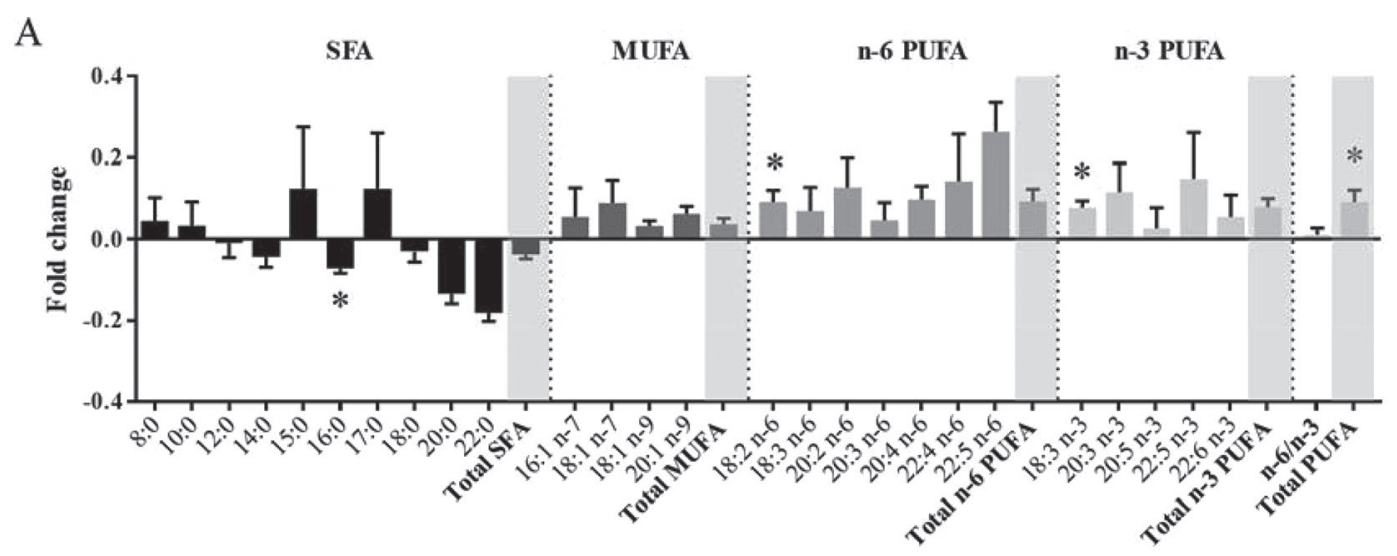

B

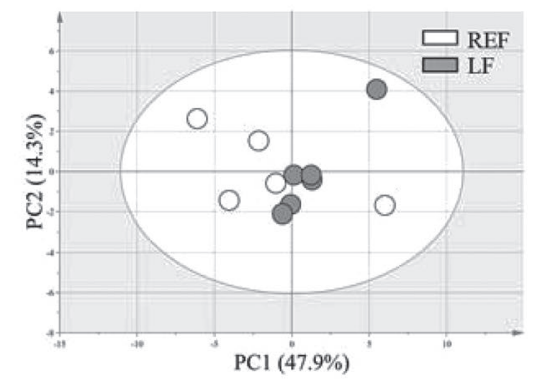

$\mathrm{C}$

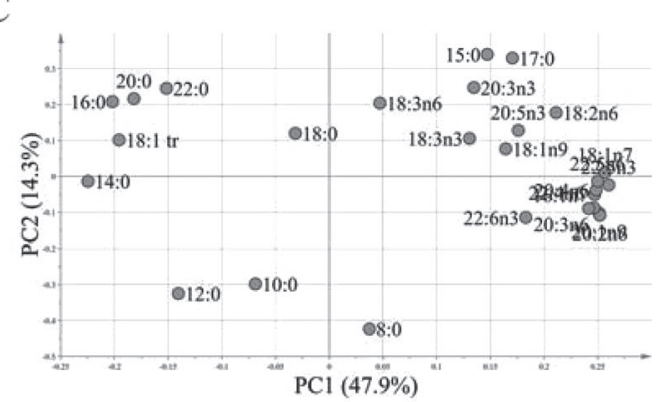

Figure 2. Effects of Lactobacillus fermentum CECT5716 (LF) supplementation on milk fatty acid (FA) proportions. (A) Changes in the milk proportion of FA due to LF supplementation. All FA data are reported as fold changes relative to the reference (REF) group. (B) Principal component analysis (PCA) score plot and (C) PCA loading scores plot of the milk FA. Results were derived from $\mathrm{n}=6$ per group. ${ }^{*} P<0.05$ versus REF. $\mathrm{PC} 1=$ principal component $1 ; \mathrm{PC} 2=$ principal component 2 . Results were derived from $\mathrm{n}=6$ per group and expressed as mean $\pm \mathrm{SEM}$.

\section{DISCUSSION}

Lactic acid bacteria, such as L. fermentum CECT5716, are present in human breast milk and gut and play an important role in promoting health of the host, including modulation of the immune response and protection against infections (Martín et al., 2003; Tsai et al., 2012). Moreover, maternal exposure to probiotics is associated with the development of a healthy microbiota, the prevention of allergy, and the nutritional status of the infant (Naaktgeboren, 2010). The present study gained insight on the effects of this probiotic strain, when administered in rats during gestation and lactation periods, in the milk profile of microbiota, FA, and immunoglobulin.

Although there are clear differences between the developmental biology of rodents and humans, (e.g., rat pups are born with a more immature gut, brain, and immune system), the present model contributes to increase the knowledge in the perinatal nutrition. Moreover, there is evidence favorable for the use of the rat in developmental biology and the suckling rat in immunonutrition studies (Puiman and Stoll, 2008; Pérez-Cano et al., 2012; Grigsby, 2016).
The presence of L. fermentum CECT5716 was confirmed in the intestine of all samples and in the half of the milk samples from the supplemented group. Moreover, all samples in the REF group were negative for the strain and one of the MG analyzed was a positive match with one of the milk samples. These results are in accordance with a study of Arroyo et al. (2010), who succeeded to isolate L. fermentum CECT5716 from milk samples of women receiving the probiotic and suffering from mastitis. Transfer of orally administered Lactobacillus from maternal gut to breast milk has been previously reported (Jiménez et al., 2008; Abrahamsson et al., 2009; Martín et al., 2012). These results are compatible with the entero-mammary pathway hypothesis, in which bacteria from the gut may be taken up by mononuclear cells in the intestine and afterward migrate to the MG and arrive to the neonate through the breast milk (Rodríguez, 2014). The fact that the detection of the strain was evidenced in only one of the MG, in contrast with the positive detection in 3 of the milk samples might not be conclusive. In this regard, since we used a small part of the MG for the analysis, we cannot discard the possibility that the bacteria could be present in other parts of the large mammary 
tissue. To confirm these results, future research should be performed with a more focused experimental design to evidence the translocation of the probiotic and using a larger sample size. However, we suggest that this transference is not critical for the effects found here on the bioactive components studied, because we did not detect any clear correlation between the outcomes and positive detection of $L$. fermentum CECT5716 in milk.

The supplementation with L. fermentum CECT5716 did not induce relevant changes in the microbiota composition of milk compared with the REF group. We detected a few minor populations that were only present when supplementing with the probiotic, but not in all samples. This finding is in line with other studies that fail to find microbial changes already at the intestinal level using this strain in the context of health (Díaz-Ropero et al., 2007; Maldonado-Lobón et al., 2015b). In contrast, other studies report that administration of L. fermentum CECT5716 is an effective strategy to prevent dysbiosis in the context of disease, such as mastitis or hypertension (Maldonado-Lobón et al., 2015a; Robles-Vera et al., 2018).

The supplementation with L. fermentum CECT5716 induced changes in the FA milk profile. The proportion of palmitic acid was lower in the LF group, and conversely, the proportion of total PUFA increased due to higher proportions of linoleic acid and $\alpha$-linolenic acids. These results are in accordance with other studies in goats that also showed increase in linoleic and $\alpha$-linolenic acids after the daily supplementation with Lactobacillus plantarum PCA 236 (Maragkoudakis et al., 2010) and an increase in linoleic acid and a decrease in palmitic acid after the supplementation with a mixture of potentially probiotic bacteria containing

\section{A}

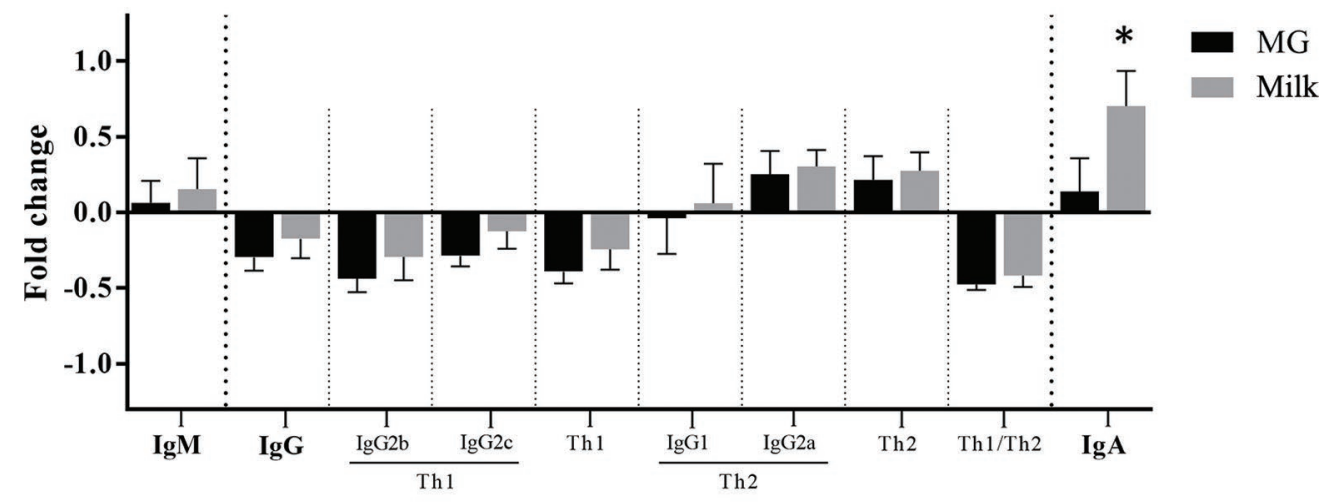

$\mathrm{B}$

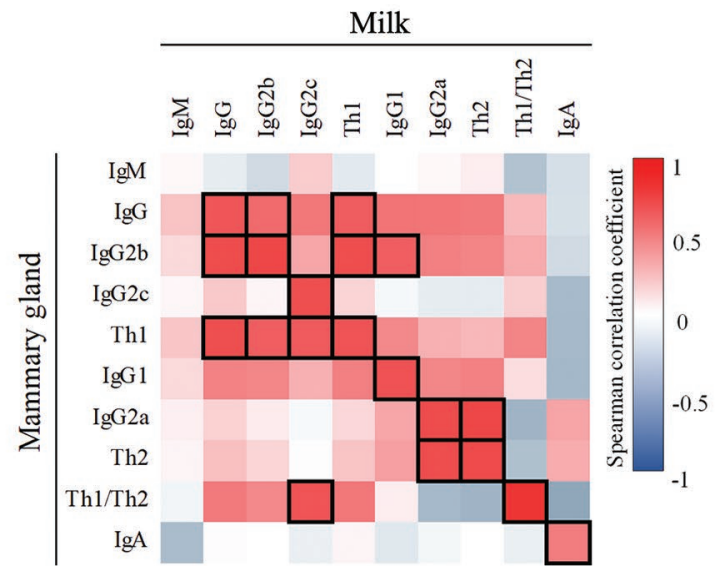

Figure 3. Effects of Lactobacillus fermentum CECT5716 (LF) supplementation on the mammary gland and milk immunoglobulin concentration. (A) Changes in the mammary gland and milk proportion of immunoglobulin due to LF supplementation. All immunoglobulin data are reported as fold changes relative to the reference (REF) group. (B) Correlation between the immunoglobulin content in the mammary gland and milk. The Spearman correlation coefficient $(n=6)$ is represented in a heat map following the color in the legend. Correlations with statistical significance $(P<0.05)$ are shown in a bold frame. Results were derived from $\mathrm{n}=6$ per group. ${ }^{*} P<0.05$ versus REF. MG $=$ mammary gland; Th1 $=$ T-helper 1 ; Th2 $=$ T-helper 2 . Results were derived from $\mathrm{n}=6$ per group and expressed as mean \pm SEM. 
Lactobacillus (Apás et al., 2015). In the same context, L. fermentum strains originated from milk have also shown cholesterol-lowering effects in vitro (Asan-Ozusaglam and Gunyakti, 2018).

The PUFA in breast milk are derived from the diet, maternal body stores, or endogenous production from precursor FA (Sauerwald et al., 2001). In this regard, long-chain FA from the diet, such as palmitic or linoleic acids, contribute around $30 \%$ of the fat in the milk (Sauerwald et al., 2001). Although the mechanism of FA modulation deserves to be further investigated for this specific strain, this effect could be associated with the potential of probiotics to modulate the nutrient digestion process, absorption, or lipid metabolism (Kankaanpää et al., 2004; Maragkoudakis et al., 2010; Zhang and Zhang, 2013). Indeed, probiotics may influence fat absorption because they can interact and modify bile salts or even hydrolyze them (Li, 2012). Moreover, several studies have reported that probiotics can regulate lipid metabolism by modulating the expression of peroxisome proliferator-activated receptors (Aronsson et al., 2010; Zhao et al., 2012), the activation of nitric oxide synthase (Korhonen et al., 2001; Ulisse et al., 2001), or the activity of the autonomic nervous system (Tanida et al., 2008).

Therefore, this increase in PUFA induced by $L$. fermentum CECT5716 supplementation enhances the quality of breast milk because PUFA are pivotal for the newborn. Linoleic and $\alpha$-linolenic acids are essential FA and the first precursors needed for the conversion cascade in the generation of very long-chain PUFA, which are important in the development and growth of infants (Emmett and Rogers, 1997; Fu et al., 2016). In line with this, some studies have exhibited lower amounts of PUFA in breast milk of allergic mothers (Sala-Vila et al., 2008). However, the evidence that higher PUFA intake reduces the risk of allergic diseases in childhood is still low (Schindler et al., 2016).

In the present study we found that L. fermentum CECT5716 induced a 2-fold increase of the amount of IgA in milk. Although such an increase was not observed in the $\mathrm{MG}$, we observed positive correlations between the levels of $\operatorname{IgA}$ (and $\operatorname{IgG}$ ) in both compartments. Immunoglobulin A is the main immunoglobulin found in mucosal sites and it is involved in the protection against infections (Cerutti et al., 2011). Several studies assessing the effects of Lactobacillus strains, such as Lactobacillus GG or Lactobacillus casei subsp. rhamnosus GG, found an increase in plasma specific and nonspecific IgA in children suffering from rotavirus diarrhea (Kaila et al., 1992; Majamaa et al., 1995).

Conversely to what we found here, Maldonado-Lobón et al. (2015a) did not find differences in breast milk
IgA after supplementing lactating women suffering breast pain for 3 wk. Besides the strain-specific effect, this could suggest that the supplementation during the gestation period could play a key role for the changes linked to the enhancement of $\operatorname{IgA}$ production found here. In addition, other studies showed that L. fermentum CECT5716 induced an increase in plasma-specific IgA in adults vaccinated against influenza virus (Olivares et al., 2007) and an increase in fecal but not plasma IgA in mice (Díaz-Ropero et al., 2007). Despite that, no changes were observed in the fecal IgA concentration in children (Maldonado et al., 2012; Maldonado-Lobón et al., 2015b).

The mechanism by which $L$. fermentum CECT5716 increased IgA in milk needs to be further investigated. Some probiotic microorganisms have shown to increase the IgA cycle and promote T-independent IgA induction (Maldonado Galdeano et al., 2007). In fact, this strain has shown immunomodulation properties in humans, in vivo and in vitro, that could explain the changes in $\mathrm{IgA}$, for example by increasing the activation of natural killer and T cells, the expansion of regulatory $\mathrm{T}$ cells, and the induction of many cytokines, such as IL-10 (Díaz-Ropero et al., 2007; Olivares et al., 2007; Pérez-Cano et al., 2010; Maldonado-Lobón et al., 2015a; Rodríguez-Nogales et al., 2015; Robles-Vera et al., 2018).

Evidence indicates that probiotic lactobacilli influence IgA secretion and IgA-secreting cells. In particular, $\operatorname{IgA} \mathrm{A}^{+} \mathrm{B}$ cells induced at the intestinal level can migrate to the $\mathrm{MG}$ toward the end of gestation and throughout the lactation period (Brandtzaeg, 2003; Martín et al., 2004; Bourges et al., 2008). Therefore, this demonstrates the need to start supplementation already at the pregnancy period. In the last instance, the increase in total nonspecific IgA in breast milk might be important for the establishment of immunity in the newborn and suggests that infants would be more protected against enteric infections.

Overall, no differences in FA profile or IgA levels were detected between supplemented rats with positive detection in milk compared with those that were negative for the probiotic. This fact suggests that the beneficial effects of this probiotic are orchestrated in the gut and it is independent of the probiotic migration to the MG and milk.

\section{CONCLUSIONS}

We found that supplementation with L. fermentum CECT5716 during gestation and 2 wk of lactation induced beneficial effects on milk composition of rats. Although the milk microbiota was not modified, the 
probiotic was able to reach the milk. Independent of the probiotic arrival, the quality of milk was enhanced in terms of FA due to an increase in PUFA content. Moreover, the probiotic exerted a positive effect by inducing a 2 -fold increment of the amount of $\operatorname{IgA}$. These findings provide novel insight for the use of probiotics in the enhancement of the breast milk quality of mothers whose offspring might benefit from better nutrition, development of a healthy immune system and microbiota, and protection from gastrointestinal infections.

\section{ACKNOWLEDGMENTS}

The present study was supported by a grant from the Institute for Research on Nutrition and Food Safety (FRI2015) and the project DIM-2-ELI from "Marató de TV3" foundation (2018-27-30). The authors thank Jaume Comas Riu (CCiT-UB) for his help and advice with the Luminex in the CCiT-UB. The probiotic strains used in the study were a gift from Biosearch Life (Granada, Spain). The authors have not stated any conflicts of interest.

\section{REFERENCES}

Abrahamsson, T. R., G. Sinkiewicz, T. Jakobsson, M. Fredrikson, and B. Bjorkstén. 2009. Probiotic lactobacilli in breast milk and infant stool in relation to oral intake during the first year of life. J. Pediatr. Gastroenterol. Nutr. 49:349-354. https://doi.org/10.1097/ MPG.0b013e31818f091b.

Apás, A. L., M. E. Arena, S. Colombo, and S. N. González. 2015. Probiotic administration modifies the milk fatty acid profile, intestinal morphology, and intestinal fatty acid profile of goats. J. Dairy Sci. 98:47-54. https://doi.org/10.3168/jds.2013-7805.

Archer, A. C., and P. M. Halami. 2015. Probiotic attributes of Lactobacillus fermentum isolated from human feces and dairy products. Appl. Microbiol. Biotechnol. 99:8113-8123. https://doi.org/ 10.1007/s00253-015-6679-x.

Aronsson, L., Y. Huang, P. Parini, M. Korach-André, J. Håkansson, J. Å. Gustafsson, S. Pettersson, V. Arulampalam, and J. Rafter. 2010. Decreased fat storage by Lactobacillus paracasei is associated with increased levels of angiopoietin-like 4 protein (ANGPTL4). PLoS One 5:e13087. https://doi.org/10.1371/journal.pone .0013087 .

Arroyo, R., V. Martín, A. Maldonado, E. Jiménez, L. Fernández, and J. M. Rodríguez. 2010. Treatment of infectious mastitis during lactation: Antibiotics versus oral administration of lactobacilli isolated from breast milk. Clin. Infect. Dis. 50:1551-1558. https://doi .org $/ 10.1086 / 652763$.

Asan-Ozusaglam, M., and A. Gunyakti. 2018. Lactobacillus fermentum strains from human breast milk with probiotic properties and cholesterol-lowering effects. Food Sci. Biotechnol. 28:501-509. https:/ /doi.org/10.1007/s10068-018-0494-y.

Azagra-Boronat, I., M. Massot-Cladera, K. Knipping, B. van’t Land, B. Stahl, J. Garssen, M. J. Rodríguez-Lagunas, À. Franch, M. Castell, and F. J. Pérez-Cano. 2018. Supplementation with 2'-FL and scGOS/lcFOS ameliorates rotavirus-induced diarrhea in suckling rats. Front. Cell. Infect. Microbiol. 8:372. https://doi.org/10.3389/ fcimb.2018.00372.

Ballard, O., and A. L. Morrow. 2013. Human milk composition: Nutrients and bioactive factors. Pediatr. Clin. North Am. 60:49-74. https://doi.org/10.1016/j.pcl.2012.10.002.
Bond, D. M., J. M. Morris, and N. Nassar. 2017. Study protocol: Evaluation of the probiotic Lactobacillus fermentum CECT5716 for the prevention of mastitis in breastfeeding women: A randomised controlled trial. BMC Pregnancy Childbirth 17:148. https://doi .org/10.1186/s12884-017-1330-8.

Bourges, D., F. Meurens, M. Berri, C. Chevaleyre, G. Zanello, B. Levast, S. Melo, V. Gerdts, and H. Salmon. 2008. New insights into the dual recruitment of IgA + B cells in the developing mammary gland. Mol. Immunol. 45:3354-3362. https://doi.org/10.1016/j .molimm.2008.04.017.

Brandtzaeg, P. 2003. Mucosal immunity: Integration between mother and the breast-fed infant. Vaccine 21:3382-3388. https://doi.org/ 10.1016/S0264-410X(03)00338-4.

Cerutti, A., K. Chen, and A. Chorny. 2011. Immunoglobulin responses at the mucosal interface. Annu. Rev. Immunol. 29:273-293. https: //doi.org/10.1146/annurev-immunol-031210-101317.

Díaz-Ropero, M. P., R. Martín, S. Sierra, F. Lara-Villoslada, J. M. Rodríguez, J. Xaus, and M. Olivares. 2007. Two Lactobacillus strains, isolated from breast milk, differently modulate the immune response. J. Appl. Microbiol. 102:337-343. https://doi.org/10.1111/ j.1365-2672.2006.03102.x.

Emmett, P. M., and I. S. Rogers. 1997. Properties of human milk and their relationship with maternal nutrition. Early Hum. Dev. 49:S7S28. https://doi.org/10.1016/S0378-3782(97)00051-0.

Fernández, L., S. Langa, V. Martín, A. Maldonado, E. Jiménez, R. Martín, and J. M. Rodríguez. 2013. The human milk microbiota: Origin and potential roles in health and disease. Pharmacol. Res. 69:1-10. https://doi.org/10.1016/j.phrs.2012.09.001.

Fu, Y., X. Liu, B. Zhou, A. C. Jiang, and L. Chai. 2016. An updated review of worldwide levels of docosahexaenoic and arachidonic acid in human breast milk by region. Public Health Nutr. 19:26752687. https://doi.org/10.1017/S1368980016000707.

Ganapathy, S. 2009. Long chain polyunsaturated fatty acids and immunity in infants. Indian Pediatr. 46:785-790.

Gil-Campos, M., M. Á. López, M. V. Rodriguez-Benítez, J. Romero, I. Roncero, M. D. Linares, J. Maldonado, E. López-Huertas, R. Berwind, K. L. Ritzenthaler, V. Navas, C. Sierra, L. Sempere, A. Geerlings, J. A. Maldonado-Lobón, A. D. Valero, F. Lara-Villoslada, and M. Olivares. 2012. Lactobacillus fermentum CECT 5716 is safe and well tolerated in infants of 1-6 months of age: A randomized controlled trial. Pharmacol. Res. 65:231-238. https://doi.org/ 10.1016/j.phrs.2011.11.016.

Gottrand, F. 2008. Long-chain polyunsaturated fatty acids influence the immune system of infants. J. Nutr. 138:1807S-1812S. https:// doi.org/10.1093/jn/138.9.1807S.

Gregora, M. 2018. Lactobacillus species in breast milk. ProbioticsCurrent Knowledge and Future Prospects. S. Enany, ed. Chapter 6:107-114. https://doi.org/10.5772/intechopen.72639.

Grigsby, P. L. 2016. Animal models to study placental development and function throughout normal and dysfunctional human pregnancy. Semin. Reprod. Med. 34:11-16. https://doi.org/10.1055/s $-0035-1570031$.

Jackson, K. M., and A. M. Nazar. 2006. Breastfeeding, the immune response, and long-term health. J. Am. Osteopath. Assoc. 106:203207.

Jeurink, P. V., J. van Bergenhenegouwen, E. Jiménez, L. M. J. Knippels, L. Fernández, J. Garssen, J. Knol, J. M. Rodríguez, and R. Martín. 2013. Human milk: A source of more life than we imagine. Benef. Microbes 4:17-30. https://doi.org/10.3920/BM2012.0040.

Jiménez, E., L. Fernández, A. Maldonado, R. Martín, M. Olivares, J. Xaus, and J. M. Rodríguez. 2008. Oral Administration of Lactobacillus strains isolated from breast milk as an alternative for the treatment of infectious mastitis during lactation. Appl. Environ. Microbiol. 74:4650-4655. https://doi.org/10.1128/AEM.02599-07.

Jiménez, E., S. Langa, V. Martín, R. Arroyo, R. Martín, L. Fernández, and J. M. Rodríguez. 2010. Complete genome sequence of Lactobacillus fermentum CECT 5716 , a probiotic strain isolated from human milk. J. Bacteriol. 192:4800. https://doi.org/10.1128/JB .00702-10.

Kaila, M., E. Isolauri, E. Soppi, E. Virtanen, S. Laine, and H. Arvilommi. 1992. Enhancement of the circulating antibody secreting 
cell response in human diarrhea by a human Lactobacillus strain. Pediatr. Res. 32:141-144. https://doi.org/10.1203/00006450 -199208000-00002.

Kankaanpää, P., B. Yang, H. Kallio, E. Isolauri, and S. Salminen. 2004. Effects of polyunsaturated fatty acids in growth medium on lipid composition and on physicochemical surface properties of lactobacilli. Appl. Environ. Microbiol. 70:129-136. https://doi .org/10.1128/AEM.70.1.129-136.2004.

Koletzko, B. 2016. Human milk lipids. Ann. Nutr. Metab. 69:28-40. https://doi.org/10.1159/000452819.

Korhonen, R., R. Korpela, M. Saxelin, M. Mäki, H. Kankaanranta, and E. Moilanen. 2001. Induction of nitric oxide synthesis by probiotic Lactobacillus rhamnosus GG in J774 macrophages and human t84 intestinal epithelial cells. Inflammation 25:223-232. https: //doi.org/10.1023/A:1010971703271.

Li, G. 2012. Intestinal probiotics: Interactions with bile salts and reduction of cholesterol. Procedia Environ. Sci. 12:1180-1186. https: //doi.org/10.1016/j.proenv.2012.01.405.

Majamaa, H., E. Isolauri, M. Saxelin, and T. Vesikari. 1995. Lactic acid bacteria in the treatment of acute rotavirus gastroenteritis. J. Pediatr. Gastroenterol. Nutr. 20:333-338. https://doi.org/10 $.1097 / 00005176-199504000-00012$

Maldonado, J., F. Cañabate, L. Sempere, F. Vela, A. R. Sánchez, E. Narbona, E. López-Huertas, A. Geerlings, A. D. Valero, M. Olivares, and F. Lara-Villoslada. 2012. Human milk probiotic Lactobacillus fermentum CECT5716 reduces the incidence of gastrointestinal and upper respiratory tract infections in infants. J. Pediatr. Gastroenterol. Nutr. 54:55-61. https://doi.org/10.1097/ MPG.0b013e3182333f18.

Maldonado Galdeano, C., A. De Moreno De Leblanc, G. Vinderola, M. E. Bibas Bonet, and G. Perdigón. 2007. Proposed model: Mechanisms of immunomodulation induced by probiotic bacteria. Clin. Vaccine Immunol. 14:485-492. https://doi.org/10.1128/CVI.00406 -06 .

Maldonado-Lobón, J. A., M. A. Díaz-López, R. Carputo, P. Duarte, M. P. Díaz-Ropero, A. D. Valero, A. Sañudo, L. Sempere, M. D. Ruiz-López, Ó. Bañuelos, J. Fonollá, and M. Olivares Martín. 2015a. Lactobacillus fermentum CECT 5716 reduces Staphylococcus load in the breastmilk of lactating mothers suffering breast pain: A randomized controlled trial. Breastfeed. Med. 10:425-432. https://doi.org/10.1089/bfm.2015.0070.

Maldonado-Lobón, J. A., M. Gil-Campos, J. Maldonado, E. LópezHuertas, K. Flores-Rojas, A. D. Valero, M. V. Rodríguez-Benítez, O. Bañuelos, F. Lara-Villoslada, J. Fonollá, and M. Olivares. 2015b. Long-term safety of early consumption of Lactobacillus fermentum CECT5716: A 3-year follow-up of a randomized controlled trial. Pharmacol. Res. 95-96:12-19. https://doi.org/10.1016/j.phrs 2015.01.006

Maragkoudakis, P. A., K. C. Mountzouris, C. Rosu, G. Zoumpopoulou, K. Papadimitriou, E. Dalaka, A. Hadjipetrou, G. Theofanous, G. P. Strozzi, N. Carlini, G. Zervas, and E. Tsakalidou. 2010. Feed supplementation of Lactobacillus plantarum PCA 236 modulates gut microbiota and milk fatty acid composition in dairy goats - A preliminary study. Int. J. Food Microbiol. 141:S109-S116. https:// doi.org/10.1016/j.ijfoodmicro.2010.03.007.

Martin, M. 2011. Cutadapt removes adapter sequences from highthroughput sequencing reads. EMBnet.journal 17:10-12.

Martín, R., S. Langa, C. Reviriego, E. Jimínez, M. L. Marín, M. Olivares, J. Boza, J. Jiménez, L. Fernández, J. Xaus, and J. M. Rodríguez. 2004. The commensal microflora of human milk: New perspectives for food bacteriotherapy and probiotics. Trends Food Sci. Technol. 15:121-127. https://doi.org/10.1016/j.tifs.2003.09 .010 .

Martín, R., S. Langa, C. Reviriego, E. Jiménez, M. L. Marín, J. Xaus, L. Fernández, and J. M. Rodríguez. 2003. Human milk is a source of lactic acid bacteria for the infant gut. J. Pediatr. 143:754-758. https://doi.org/10.1016/j.jpeds.2003.09.028.

Martín, V., A. Maldonado-Barragán, L. Moles, M. Rodriguez-Baños, R. Del Campo, L. Fernández, J. M. Rodríguez, and E. Jiménez. 2012. Sharing of bacterial strains between breast milk and infant feces. J. Hum. Lact. 28:36-44. https://doi.org/10.1177/ 0890334411424729.

McFarland, L. V., C. T. Evans, and E. J. C. Goldstein. 2018. Strainspecificity and disease-specificity of probiotic efficacy: A systematic review and meta-analysis. Front. Med. (Lausanne) 5:124. https: //doi.org/10.3389/fmed.2018.00124.

Mecacci, F., S. Biagioni, S. Ottanelli, and G. Mello. 2015. Nutrition in pregnancy and lactation: How a healthy infant is born. J. Pediatr. Neonatal Individ. Med. 4:e040236. https://doi.org/10.7363/ 040236 .

Naaktgeboren, C. A. 2010. Effects of maternal probiotic exposure during pregnancy and lactation on the mother and infant. Int. J. Probiotics Prebiotics 5:113-124.

Olivares, M., M. P. Díaz-Ropero, S. Sierra, F. Lara-Villoslada, J. Fonollá, M. Navas, J. M. Rodríguez, and J. Xaus. 2007. Oral intake of Lactobacillus fermentum CECT5716 enhances the effects of influenza vaccination. Nutrition 23:254-260. https://doi.org/10 .1016/j.nut.2007.01.004.

Pérez-Cano, F. J., H. Dong, and P. Yaqoob. 2010. In vitro immunomodulatory activity of Lactobacillus fermentum CECT5716 and Lactobacillus salivarius CECT5713: Two probiotic strains isolated from human breast milk. Immunobiology 215:996-1004. https:// doi.org/10.1016/j.imbio.2010.01.004.

Pérez-Cano, F. J., A. Franch, C. Castellote, and M. Castell. 2012. The suckling rat as a model for immunonutrition studies in early life. Clin. Dev. Immunol. 2012:537310. https://doi.org/10.1155/2012/ 537310.

Puiman, P., and B. Stoll. 2008. Animal models to study neonatal nutrition in humans. Curr. Opin. Clin. Nutr. Metab. Care 11:601606. https://doi.org/10.1097/MCO.0b013e32830b5b15.

Ramírez-Santana, C., F. J. Pérez-Cano, C. Castellote, M. Castell, M. Rivero, M. Rodríguez-Palmero, and À. Franch. 2009. Higher immunoglobulin production in conjugated linoleic acid-supplemented rats during gestation and suckling. Br. J. Nutr. 102:858-868. https://doi.org/10.1017/S0007114509301592.

Reeves, P. G., F. H. Nielsen, and G. C. Fahey Jr... 1993. AIN-93 purified diets for laboratory rodents: Final report of the American Institute of Nutrition ad hoc Writing Committee on the reformulation of the AIN-76A rodent diet. J. Nutr. 123:1939-1951. https:// doi.org/10.1093/jn/123.11.1939.

Reid, J. N. S., J. E. Bisanz, M. Monachese, J. P. Burton, and G. Reid. 2013. The rationale for probiotics improving reproductive health and pregnancy outcome. Am. J. Reprod. Immunol. 69:558-566. https://doi.org/10.1111/aji.12086.

Robles-Vera, I., M. Toral, N. de la Visitación, M. Sánchez, M. Romero, M. Olivares, R. Jiménez, and J. Duarte. 2018. The probiotic Lactobacillus fermentum prevents dysbiosis and vascular oxidative stress in rats with hypertension induced by chronic nitric oxide blockade. Mol. Nutr. Food Res. 62:e1800298. https://doi.org/10 $.1002 /$ mnfr.201800298.

Rodríguez, J. M. 2014. The origin of human milk bacteria: Is there a bacterial entero-mammary pathway during late pregnancy and lactation? Adv. Nutr. 5:779-784. https://doi.org/10.3945/an.114 .007229 .

Rodríguez-Nogales, A., F. Algieri, T. Vezza, N. Garrido-Mesa, M. Olivares, M. Comalada, C. Riccardi, M. P. Utrilla, M. E. Rodríguez-Cabezas, and J. Galvez. 2015. The viability of Lactobacillus fermentum CECT5716 is not essential to exert intestinal anti-inflammatory properties. Food Funct. 6:1176-1184. https://doi.org/ 10.1039/C4FO00938J.

Sala-Vila, A., E. A. Miles, and P. C. Calder. 2008. Fatty acid composition abnormalities in atopic disease: evidence explored and role in the disease process examined. Clin. Exp. Allergy 38:1432-1450. https://doi.org/10.1111/j.1365-2222.2008.03072.x.

Sauerwald, T. U., H. Demmelmair, and B. Koletzko. 2001. Polyunsaturated fatty acid supply with human milk. Lipids 36:991-996. https: //doi.org/10.1007/s11745-001-0810-9.

Schindler, T., J. K. Sinn, and D. A. Osborn. 2016. Polyunsaturated fatty acid supplementation in infancy for the prevention of allergy. 
Cochrane Database Syst. Rev. 10:CD010112. https://doi.org/10 .1002/14651858.CD010112.pub2.

Swartwout, B., and X. M. Luo. 2018. Implications of probiotics on the maternal-neonatal interface: Gut microbiota, immunomodulation, and autoimmunity. Front. Immunol. 9:2840. https://doi.org/ 10.3389/fimmu.2018.02840.

Tanida, M., J. Shen, K. Maeda, Y. Horii, T. Yamano, Y. Fukushima, and K. Nagai. 2008. High-fat diet-induced obesity is attenuated by probiotic strain Lactobacillus paracasei ST11 (NCC2461) in rats. Obes. Res. Clin. Pract. 2:159-169. https://doi.org/10.1016/j.orcp .2008.04.003.

Tian, H. M., Y. X. Wu, Y. Q. Lin, X. Y. Chen, M. Yu, T. Lu, and L. Xie. 2019. Dietary patterns affect maternal macronutrient intake levels and the fatty acid profile of breast milk in lactating chinese mothers. Nutrition 58:83-88. https://doi.org/10.1016/j.nut.2018 .06.009.

Tsai, Y. T., P. C. Cheng, and T.-M. Pan. 2012. The immunomodulatory effects of lactic acid bacteria for improving immune functions and benefits. Appl. Microbiol. Biotechnol. 96:853-862. https://doi .org/10.1007/s00253-012-4407-3.

Ulisse, S., P. Gionchetti, S. D'Alò, F. P. Russo, I. Pesce, G. Ricci, F. Rizzello, U. Helwig, M. G. Cifone, M. Campieri, and C. De Simone. 2001. Expression of cytokines, inducible nitric oxide synthase, and matrix metalloproteinases in pouchitis: Effects of probiotic treatment. Am. J. Gastroenterol. 96:2691-2699. https://doi.org/ 10.1111/j.1572-0241.2001.04139.x.

Zhang, Y., and H. Zhang. 2013. The effect of probiotics on lipid metabolism. Lipid Metabolism. R. V. Baez, ed. IntechOpen Chapter 17:443-460. https://doi.org/10.5772/51938.

Zhao, X., F. Higashikawa, M. Noda, Y. Kawamura, Y. Matoba, T. Kumagai, and M. Sugiyama. 2012. The obesity and fatty liver are reduced by plant-derived Pediococcus pentosaceus LP28 in high fat diet-induced obese mice. PLoS One 7:e30696. https://doi.org/10 .1371/journal.pone.0030696.

\section{ORCIDS}

Ignasi Azagra-Boronat 우 https://orcid.org/0000-0002-3990-7502 Alba Tres (ㄴ) https://orcid.org/0000-0003-3626-8511

Malén Massot-Cladera @ https://orcid.org/0000-0002-5220-2793

Àngels Franch (1) https://orcid.org/0000-0002-2362-1374

Margarida Castell ๑ https://orcid.org/0000-0001-5408-0593

Francesc Guardiola @ https://orcid.org/0000-0002-8624-8749

Francisco J. Pérez-Cano ® https://orcid.org/0000-0001-6243-9164

M. José Rodríguez-Lagunas ํ https://orcid.org/0000-0001-7870-8250 